\title{
APPLICATION OF COPULAS TO MODELLING OF MARRIAGE REVERSE ANNUITY CONTRACT*
}

\author{
Joanna Dębickaa , Stanisław Heilperna ${ }^{a}$ Agnieszka Marciniuk ${ }^{a}$
}

\begin{abstract}
We model the probabilistic structure and cash flows arising from marriage reverse annuity contracts in the case of the joint-life status and the last surviving status. In contrast to the classical approach, we take into consideration that future lifetimes between spouses are dependent. The structure of dependence of the length of spouses' lives is modelled using copulas. The term structure of interest rate is modelled using a time-dependent function. The numerical results are based on actual Polish data covering both the structure of the probabilistic model and the interest rate.
\end{abstract}

Keywords: Longevity risk, dependent lifetimes, reverse annuity contract, selling model, multistate model, copula, equity release contracts

JEL Classification: C60, G17, G22, J10

\section{Introduction and Motivation}

Life expectancy has been increasing in almost all the countries of the world (Blake et al., 2013). Therefore, it is natural that people expect longer lifetimes and pension, annuity or other benefits. This situation creates the risk of insolvency of pension systems or bankruptcies of insurance companies when it turns out that they should pay benefits longer or at a different level than they expected (Potocký et al., 2014). The longevity risk can be hedged, for example, with longevity bonds having coupons proportional to the number of cohort survivors at each anniversary after the issue date; see, e.g., Stallard (2006). However, more such solutions exist. Longevity risk and related capital market solutions have become increasingly important in recent years (Blake et al., 2013; Blake and Morales 2017).

a Wroclaw University of Economics, Faculty of Management, Computer Science and Finance, Poland Email: joanna.debicka@ue.wroc.pl; stanislaw.heilpern@ue.wroc.pl;

agnieszka.marciniuk@ue.wroc.pl

* Partial financial support from grant no. 2013/09/B/HS4/00490 "Non-Standard Multilife Insurance Products with Dependence Between Insured" is gratefully acknowledged.

This article is partially based on a talk presented at the ASTIN Colloquium Lisboa 2016

http://m.actuaries.org/lisbon2016/presentations/Lisbon36_AMarciniuk_marriagereverse.pdf 
Sometimes the retirement benefits due to social insurance are low. This is the reason that the society needs additional financial resources. Many people have own apartments or homes, but most of them do not want to sell their properties and move from their place. Therefore, markets in different countries propose the so-called equity release products for retirees (Hanewald et al., 2016). The two main types of these products are the loan model (reverse mortgage scheme) and the sale model (home reversion scheme). Different varieties of these products exist in many countries (Shao et al., 2015). We focus on one of them, i.e., the reverse annuity contract (a sale model), which exists in individual form in Poland.

The reverse annuity contract is a benefit that an owner can receive in exchange for renunciation of his/her rights to a real estate to a company (mortgage fund in Poland), created especially for this purpose. This contract is offered to elderly people. By a notarial act, the owner is guaranteed the right to stay in the property until his/her death; however, he/ she formally is not the owner of the property. Because often both spouses are the property owners, our research concerns the marriage reverse annuity contract. This is a new product and it is not currently offered in Poland.

A marriage reverse annuity contract is a variation on the individual reverse annuity contract. Under these contracts, annuity benefits are payable when both spouses are alive and sometimes after the death of whichever spouse. Thus, we distinguish between two types of such contracts: a joint-life status contract, when the benefit is paid only until the death of the first spouse and a last surviving status contract, by which the benefit is paid until the death of the other spouse. These two special cases can also be described using marriage life annuity, i.e., reversionary annuity (Luciano et al., 2016). We have to remember that the reverse annuity contract is also not the same as reversionary annuity. Reverse annuity is an equity release product and reversionary annuity is a marriage life annuity.

Multiple state modelling is a stochastic tool to design and implement insurance contracts (Haberman and Pitacco, 2014). Then we apply a multiple state model for marriage insurances to model the marriage reverse annuity contract. We focus on a discrete-time model, where annuity is paid at the beginning of particular time units. We assume that the evolution of the contracted risk is described by a time-nonhomogeneous Markov chain. Moreover, actuarial values are considered under the assumption of different types of interest rate.

The aim of this article is to model the probabilistic structure and cash flows arising from marriage reverse annuity contracts. It is well known that the value of annuity depends on the mortality probabilities and term structure of interest rates. Note that the analysis of multilife contracts is usually based on the assumption of independence between the insured. In contrast to this classical approach, dependence of future lifetimes between spouses is assumed. It is a more realistic assumption than independence, because 
the husband and the wife are exposed to the same risks, which cause the dependence of their future lifetimes. We may observe the influence of a spouse's death on the other one's future lifetime. The "broken heart syndrome" occurs in such situations. Moreover, a common external event called a "shock", e.g., a car or airplane crash, which causes both spouses' death, may occur. To model the dependency, Norberg (1989), Norberg (2002) and Denuit et al. (2001) applied a stochastic process, in particular the Markov chain. We applied copulas to model the dependence structure of the length of the spouses' lives. The modelling of spouses' life lengths taking into account the dependence using a copula was considered, for example, by Carriere (2000), Gourieoux and $\mathrm{Lu}$ (2015), Luciano et al. (2008), Luciano et al. (2016) and Spreeuw (2006). Moreover, Gourieoux and Lu (2015), Luciano et al. (2016) and Spreeuw (2006) have applied these copulas to determine the actuarial value of different kinds of life annuities. However, according to our discernment, no application of these copulas to the calculation of the value of the marriage reverse annuity contract has been found in the literature. We hope that this article will bridge the gap in the marriage insurance research.

The paper is organized as follows. After this introductory section, Section 2 describes the multiple state model for marriage reverse annuity contracts according to both statuses and its probabilistic structure. We provide a formula for the annuity due benefits for the marriage reverse annuity contract in the case of both statuses.

Section 3 presents the main result in Theorem 1, where we derive formulas for elements of vectors describing the probabilistic structure of the model (introduced in Section 2) in the whole contract under the assumption that future lifetimes of spouses are dependent and modelled by copulas.

Section 4 presents some numerical examples. The types of copulas are determined based on actual data for the Lower Silesia Voivodeship and data coming from Wroclaw cemeteries. To model the spot interest rate, we used actual Polish market data related to the yield to maturity on zero-coupon and fixed-interest bonds. For our calculations, we apply the Svensson model of spot interest rate, the parameters of which are estimated using the least-squares method. The calculations are made using own programs written in MATLAB. We compare the results obtained for dependence and independence of future lifetimes of spouses.

In the last section, we summarize our results.

\section{Reverse Annuity Contract Benefits}

Multiple state modelling is a stochastic tool to design and implement insurance contracts. Then, we apply a multiple state model for marriage insurances to model the marriage reverse annuity contract, which is graphically presented in Figure 1. 


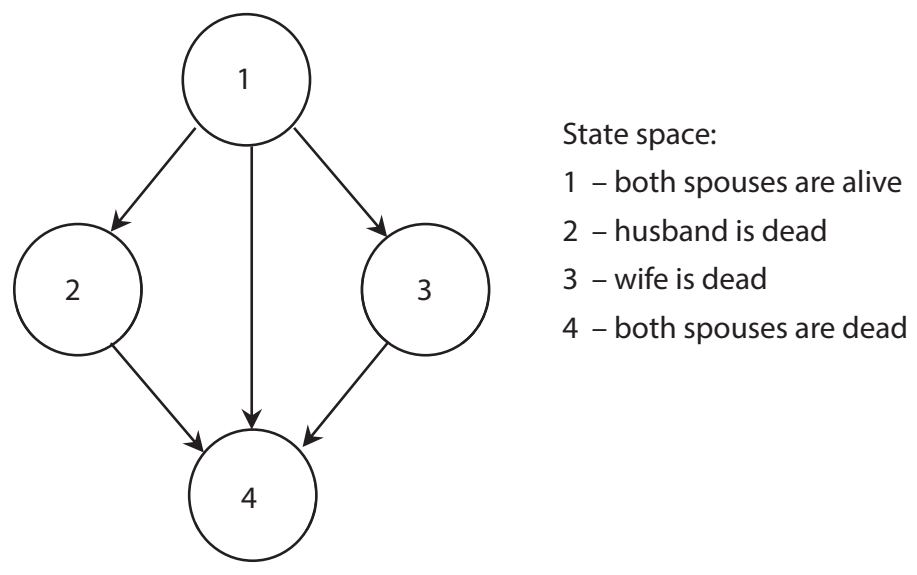

Source: Adopted from Denuit et al. (2001)

Let $\mathbf{S}$ be the state space (circles in Figure 1). Each state of $\mathbf{S}=\{1,2,3,4\}$ corresponds to an event which determines the cash flows (premiums and/or benefits). Additionally, by $\mathbf{T}=\{(1,2),(1,3),(1,4),(2,4),(3,4)\}$ we denote the set of direct transitions between states of the state space (arrows in Figure1). The pair $(\mathbf{S}, \mathbf{T})$ is called a multiple state model, and describes all possible contracted risk events up to the end of the marriage reverse annuity contract.

In our considerations, we focused on two statuses of the marriage reverse annuity contract, because of the length of the benefit received. We distinguish between:

- the joint-life status (JLS), where the benefit is paid only until the death of the first spouse,

- the last surviving status (LSS), where the benefit is paid until the death of the other spouse.

We consider a contract issued at the time 0 and terminating according to the plan at a later time $n$, which is called the term of contract or the contract period. The graphic representation of the multiple state model with statuses for an $n$-year marriage reverse annuity contract is shown in Figure 2, where $\ddot{b}$ denotes the life annuity due payable for the period $[k, k+1)(k=0,1, \ldots, n-1)$ if both spouses are alive (for state 1, i.e., if $X(k)=1$ ) or one of the spouses is alive (wife for state 2, i.e., if $X(k)=2$; husband for state 3, i.e., if $X(k)=3$ ) at the time $k$. 
A. Joint-Life Status

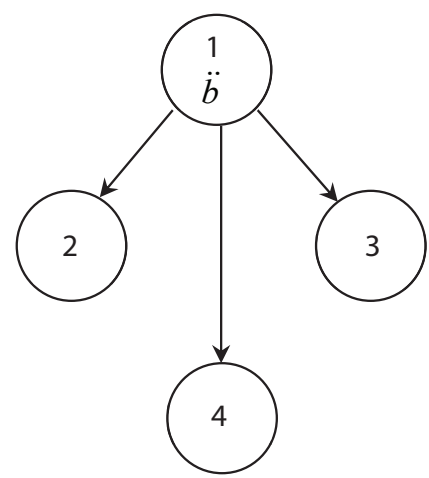

State space:

1 - both spouses are alive

2 - husband is dead

3 - wife is dead

4 - both spouses are dead
B. Last Surviving Status

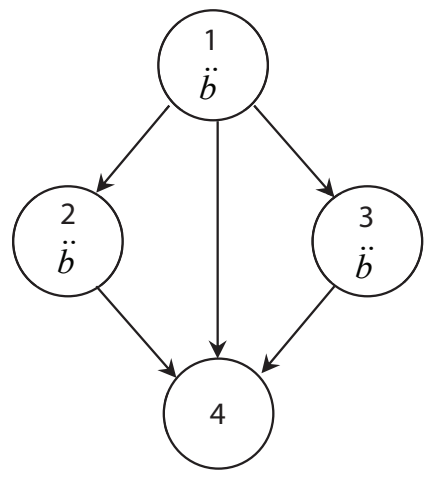

Source: Own elaboration

The multiple state model for the marriage reverse annuity contract with Joint-Life Status is included in the multiple state model with Last Surviving Status. Thus, depending on the status, annuity benefits are paid in one state (JLS) or in more than one state (LSS). Therefore, to calculate the actuarial value of annuity benefits, we need separate formulas, according to which the annuity due could be calculated for each status.

Let $(x, y)$ be the ages at the entry of an $x$-year-old husband and a $y$-year-old wife. Moreover, let $X(k)$ denote the state of the contract at the time $k(k=0,1,2, \ldots, n)$, then $X(k)=i$ means that spouses are in the state $i$ at the moment $k$. Hence, $\{X(k), k=0,1,2, \ldots, n\}$ is a discrete-time process which describes the evolution of the insured risk in the period of the contract. In order to determine the probabilistic structure of the model, we assume that $\{X(k), k=0,1,2, \ldots, n\}$ is a nonhomogeneous Markov chain (Hoem, 1969; Hoem, 1988; Wolthuis, 1994).

The type of status and ages at the entry of the husband and the wife directly influences the term of contract $n$ in the following way:

- $n=\min \left\{\omega_{x}^{M}, \omega_{y}^{W},\right\}$ for JLS,

- $n=\max \left\{\omega_{x}^{M}, \omega_{y}^{W},\right\}$ for LSS,

where $\omega_{x}^{M}$ (resp. $\omega_{y}^{W}$ ) denotes the difference between the age limit $\omega$ of the man and the woman and the man's and the woman's age at the entry $x$ and $y$, respectively.

Let $p_{i}(k)=P_{i}(X(k)=i)$ and $\mathbf{P}(k)=\left(p_{1}(k), p_{2}(k), p_{3}(k), p_{4}(k)\right)$ be the probabilities of the staying process $\{X(k), k=0,1,2, \ldots, n\}$ at the moment $k$ in one of the states belonging to the state space. $\mathbf{P}(0)=(1,0,0,0)$ is a vector of initial distribution. 
Moreover, let $\mathbf{V}$ be a vector of the $n$-th discounting factor, i.e.,

$$
\mathbf{V}=(v(0), v(1), \ldots, v(n)) \in R^{n+1} .
$$

In the case of a stochastic interest rate, $v(t)=\mathrm{E}(\exp (-Y(t)))$, where $Y(t)$ denotes the rate of interest in a time interval $[0, t]$.

If $Y(t)$ is modelled using a constant force of interest $\delta$, the process has the form $Y(t)=t \delta$. The constant discounting factor $v$ is defined as $v=e^{-\delta}$; hence, $v(k)=e^{-\delta k}=v^{k}$, for $k=0,1,2, \ldots, n$.

Let us assume that the interest rate is modelled by a time function as a spot interest rate $R(0, t)$, then $Y(t)=t \cdot R(0, t)$. For $k=1,2, \ldots, n$, the $k$-th discounting factor is given by the following formula (Lee et al., 2012; Marciniuk, 2017):

$$
v(k)=\exp (-k \cdot R(0, k)) .
$$

It is obvious that for $v(0)=1$

In the case of stochastic modelling of interest rate, $Y(t)$ could be a Gaussian stochastic process with stationary increments and a positive drift function (Dębicka, 2013). Two special cases of the process $Y(t)$ are used to model the stochastic interest rate. In the first model, it is assumed that $Y(t)=\delta W(t)+\mu t$, where $W(t)$ is a standard Wiener process, $\mu$ is the mean rate of interest and $\delta$ is the volatility. In the second model, it is assumed that $Y(t)=\int_{0}^{t} V(s) d s$, where the force of interest $V(s)$ is given by $V(s)=\delta U(s)+\mu$, with $V(s)$ an Ornstein-Uhlenbeck process.

In order to study the actuarial values, we make the following assumptions (see also Dębicka, 2013; Frees, 1990):

A1 - The random variable $X(k)$ is independent of $Y(k)$.

A2 - The first moment of the random discounting function $\exp (-Y(k))$ is finite.

Let $\ddot{a}_{i}$ denote the actuarial value of the stream of unit benefits arising from life annuity-due contract payable in the period $[0, n)$ if $X(k)=i$ for $k=0,1, \ldots, n-1$. The actuarial value is calculated at the beginning of the insurance period $(k=0)$. Under the assumption that A1-A2 hold, we have

$$
\ddot{a}_{i}=\sum_{k=0}^{n-1} v(k) \cdot p_{i}(k) \text {. }
$$

The benefit of annuity due for the marriage reverse annuity contract depends on the value of real estate $W$ and the percentage $\beta$ of the value $W$ (usually $\beta \in(0 \%, 50 \%]$ (Dębicka and Marciniuk, 2014). Thus, $\beta W$ is the capital for which the value of benefit is calculated. 
The formula for an annual benefit in an individual reverse annuity contract is given in Dębicka and Marciniuk (2014). Note that, depending on the status, annuity due benefits can be paid in any subset $\mathbf{S}^{b}$ of the set space $\mathbf{S}$. In particular, for the marriage reverse annuity contract, $\mathbf{S}^{b}=\{1\}$ for JLS and $\mathbf{S}^{b}=\{1,2,3\}$ for LSS.

Suppose that the equivalence principle holds, assumptions A1-A2 are satisfied and the annuity due benefits are paid for $k=0,1, \ldots, n-1$ if $X(k)=i$ and $i \in \mathbf{S}^{b} \subset \mathbf{S}$. Then the formula for annuity benefit $\ddot{b}_{\mathbf{s}^{b}}$ paid during the whole period has the following form:

$$
\ddot{b}_{\mathbf{S}^{b}}= \begin{cases}\frac{\beta W}{\ddot{a}_{1}} & \text { for } \quad \mathbf{S}^{b}=\{1\} \text { and } n=\min \left\{\omega_{x}^{M}, \omega_{y}^{W}\right\} \quad(\mathrm{JLS}), \\ \frac{\beta W}{\ddot{a}_{1}+\ddot{a}_{2}+\ddot{a}_{3}} & \text { for } \quad \mathbf{S}^{b}=\{1,2,3\} \text { and } n=\max \left\{\omega_{x}^{M}, \omega_{y}^{W}\right\} \quad \text { (LSS) }\end{cases}
$$

where $W$ is the value of real estate and $\beta \in(0,1]$.

Note that the assumption on dependence/independence between future lifetimes has an impact only on $p_{i}(k)$. Moreover, under assumption A1 formula (3) can be used straightforwardly for pricing annual due benefits in marriage reverse annuity contracts under the assumption that future lifetimes between spouses are dependent or independent.

\section{Probabilistic Model Structure}

In the next part of this section, probabilities $p_{i}(k)$ are derived under the assumption of dependence of spouses' future lifetimes. We introduced some notations at the beginning. Let $T_{x}^{M}$ and $T_{y}^{W}$ be the future lifetimes of an $x$-year-old man and a $y$-year-old woman, $T_{x}^{M} \in\left[0, \omega_{x}^{M}\right]$ and $T_{y}^{W} \in\left[0, \omega_{y}^{W}\right]$. Note that, according to the Life Tables, the age limit $\omega=110$ years (sometimes $\omega=110$ ). This implies that we assume in the calculations that the maximum possible duration of the marriage reverse annuity contract is equal to $\max \left\{\omega_{x}^{M}, \omega_{y}^{W},\right\}$. If the spouses are not of the same age, then the probabilities $p_{i}(k)$ at the end of the contract are reset cleanly for certain states and moments of the contract, as shown in Table 1.

The traditional approach assumes that future lifetimes of spouses are independent. In contrast, we assume dependence of future lifetimes $T_{x}^{M}$ and $T_{y}^{W}$ between the spouses. Therefore, in order to derive the probabilities $p_{i}(k)=p_{i}(X(k)=i$, for $\mathrm{i}=1,2,3,4$, we need joint distribution of lifetimes $\left(T_{x}^{M}, T_{y}^{W}\right)$. We assume that we know the cumulative distribution function $F(w, z)$ of the pair $\left(T_{x_{0}}^{M}, T_{y_{0}}^{W}\right)$, where $x_{0}$ and $y_{0}$ are reference ages for men and women, such that $x=x_{0}+s, y=y_{0}+t$ and $s, t \geq 0$. We also assume that we know the copula $C(u, v)$, the link between the joint and marginal cumulative distribution function, connected with this joint distribution, i.e., 
Table 1: Form of vector $P(k)=\left(p_{1}(k), p_{2}(k), p_{3}(k), p_{4}(k)\right)$, depending on spouses' age and contract duration

\begin{tabular}{l|c|c}
\hline$(x, y)$ & $\begin{array}{c}k=1,2, \ldots, \min \left\{\omega_{x}^{M}, \omega_{y}^{W}\right\}-1 \\
\left(x+k>\omega_{x}^{M}, \text { and } y+k>\omega_{y}^{W},\right)\end{array}$ & $\begin{array}{c}k=\min \left\{\omega_{x}^{M}, \omega_{y}^{W}\right\}, \ldots, \max \left\{\omega_{x}^{M}, \omega_{y}^{W}\right\} \\
\left(x+k>\omega_{x}^{M}, \text { and } / \text { or } y+k>\omega_{y}^{W},\right)\end{array}$ \\
\hline$x=y$ & $\mathbf{P}(k)=\left(p_{1}(k), p_{2}(k), p_{3}(k), p_{4}(k)\right)$ & $\mathbf{P}(k)=(0,0,0,1)$ \\
\hline$x>y$ & $\mathbf{P}(k)=\left(p_{1}(k), p_{2}(k), p_{3}(k), p_{4}(k)\right)$ & $\mathbf{P}(k)=\left(0,0, p_{3}(k), p_{4}(k)\right)$ \\
\hline$x<y$ & $\mathbf{P}(k)=\left(p_{1}(k), p_{2}(k), p_{3}(k), p_{4}(k)\right)$ & $\mathbf{P}(k)=\left(0, p_{2}(k), 0, p_{4}(k)\right)$ \\
\hline
\end{tabular}

Source: Own elaboration

$$
F(w, z)=C\left(F^{M}(w), F^{W}(z)\right),
$$

where $F^{M}(w)=\mathrm{P}\left(T_{x_{0}}^{M} \leq w\right)$ and $F^{W}(z)=\mathrm{P}\left(T_{y_{0}}^{W} \leq z\right)$ are the marginal distributions of the lifetimes $T_{x_{0}}^{M}$ and $T_{y_{0}}^{W}$.

However, we need the following survival function for the actuarial calculation:

$$
S(w, z)=\mathrm{P}\left(T_{x_{0}}^{M}>w, T_{y_{0}}^{W}>z\right) .
$$

Note that the dependence of spouses' lifetimes starts from the ages $x_{0}$ and $y_{0}$. Members of a couple do not have common genes. They usually did not grow up in the same household. Therefore, it does not seem too unrealistic to assume that future lifetimes of spouses are independent until they first meet (Luciano et al., 2008).

The joint survival function $S(w, z)$ can be determined using the survival copula $C^{*}(w, z)$ as follows:

$$
S(w, z)=C^{*}\left(S^{M}(w), S^{W}(z)\right)
$$

where $S^{M}(w)=\mathrm{P}\left(T_{x_{0}}^{M}>w\right), S^{W}(z)=\mathrm{P}\left(T_{y_{0}}^{W}>z\right)$ (Nelsen, 1999)

$$
C^{*}(w, z)=w+z-1+C(1-w, 1-z) .
$$

The following theorem allows us to determine the probabilities $p_{i}(k)$.

\section{Theorem 1}

Assume that the copula $C^{*}(w, z)$ is the link between the joint and marginal survival function for $x_{0}$-year-old men and $y_{0}$-year-old women. In addition, $\{X(k), t \in \mathrm{T}\}$ is a nonhomogeneous Markov chain describing evolution of the insured risk in the multistate model $(\mathbf{S}, \mathbf{T})=(\{1,2,3,4\},\{(1,2),(1,3),(1,4),(2,4),(3,4)\})$ for the marriage reverse annuity 
contract. Then, the elements of the vector $\mathbf{P}(k)=\left(p_{1}(k), p_{2}(k), p_{3}(k), p_{4}(k)\right)$ containing joint probabilities for $x+k$-year-old man and $y+k$-year-old woman have the following form:

$$
\begin{aligned}
& p_{1}(k)=\frac{C^{*}\left(S^{M}(s+k), S^{W}(t+k)\right)}{C^{*}\left(S^{M}(s), S^{W}(t)\right)}, \\
& p_{2}(k)=\frac{C^{*}\left(S^{M}(s), S^{W}(t+k)\right)-C^{*}\left(S^{M}(s+k), S^{W}(t+k)\right)}{C^{*}\left(S^{M}(s), S^{W}(t)\right)}, \\
& p_{3}(k)=\frac{C^{*}\left(S^{M}(s+k), S^{W}(t)\right)-C^{*}\left(S^{M}(s+k), S^{W}(t+k)\right)}{C^{*}\left(S^{M}(s), S^{W}(t)\right)}, \\
& p_{4}(k)=\frac{C^{*}\left(S^{M}(s), S^{W}(t)\right)-C^{*}\left(S^{M}(s), S^{W}(t+k)\right)-C^{*}\left(S^{M}(s+k), S^{W}(t)\right)+C^{*}\left(S^{M}(s+k), S^{W}(t+k)\right)}{C^{*}\left(S^{M}(s), S^{W}(t)\right)} .
\end{aligned}
$$

Proof.

The joint survival function of the lifetimes $T_{x}^{M}$ and $T_{y}^{W}$ has the following formula:

$$
\begin{aligned}
p_{1}(k) & =\mathrm{P}\left(T_{x}^{M}>k, T_{y}^{W}>k\right)=\mathrm{P}\left(T_{x_{0}}^{M}>s+k, T_{y_{0}}^{W}>t+k \mid T_{x_{0}}^{M}>s, T_{y_{0}}^{W}>t\right)= \\
& =\frac{\mathrm{P}\left(T_{x_{0}}^{M}>s+k, T_{y_{0}}^{W}>t+k\right)}{\mathrm{P}\left(T_{x_{0}}^{M}>s, T_{y_{0}}^{W}>t\right)}=\frac{S(s+k, t+k)}{S(s, t)}=\frac{C^{*}\left(S^{M}(s+k), S^{W}(t+k)\right)}{C^{*}\left(S^{M}(s), S^{W}(t)\right)} .
\end{aligned}
$$

Similarly, we obtain

$$
\begin{aligned}
p_{2}(k) & =\mathrm{P}\left(T_{x}^{M} \leq k, T_{y}^{W}>k\right)=P\left(T_{x_{0}}^{M} \leq s+k, T_{y_{0}}^{W}>t+k \mid T_{x_{0}}^{M}>s, T_{y_{0}}^{W}>t\right)= \\
& =\frac{\mathrm{P}\left(s<T_{x_{0}}^{M} \leq s+k, T_{y_{0}}^{W}>t+k\right)}{\mathrm{P}\left(T_{x_{0}}^{M}>s, T_{y_{0}}^{W}>t\right)}= \\
& =\frac{\mathrm{P}\left(T_{x_{0}}^{M}>s, T_{y_{0}}^{W}>t+k\right)-\mathrm{P}\left(T_{x_{0}}^{M}>s+k, T_{y_{0}}^{W}>t+k\right)}{\mathrm{P}\left(T_{x_{0}}^{M}>s, T_{y_{0}}^{W}>t\right)}= \\
& =\frac{S(s, t+k)-S(s+k, t+k)}{S(s, t)}=\frac{C^{*}\left(S^{M}(s), S^{W}(t+k)\right)-C^{*}\left(S^{M}(s+k), S^{W}(t+k)\right)}{C^{*}\left(S^{M}(s), S^{W}(t)\right)} .
\end{aligned}
$$

Analogously to $p_{2}(k)$, we obtain $p_{3}(k)$. We obtain the recent probability using equality $p_{4}(k)=1-p_{1}(k)-p_{2}(k)-p_{3}(k)$, which completes the proof.

Note that if $w>\omega_{x_{0}}^{M}$, then $S^{M}(w)=0$ (the same for women: if $z>\omega_{y_{0}}^{W}$, then $\left.S^{W}(z)=0\right)$. Basing on this property, it is obvious that the following identity holds: 


$$
C^{*}\left(S^{M}(w), S^{W}(z)\right)=\left\{\begin{array}{ll}
C^{*}\left(S^{M}(w), S^{W}(z)\right) & \text { for } w<\omega_{x_{0}}^{M} \text { and } z<\omega_{y_{0}}^{W} \\
0 & \text { in other cases }
\end{array} .\right.
$$

Using (5) in probabilities derived in Theorem 1, one can prove that the vectors $\mathbf{P}(k)=\left(p_{1}(k), p_{2}(k), p_{3}(k), p_{4}(k)\right)$ presented in the third column of Table 1 are correct.

The classical notation for marriage life insurances (Gerber, 1995; Denuit et al., 2001) is as follows:

$$
\begin{aligned}
& { }_{k} p_{x y}=\mathrm{P}\left(T_{x}^{M}>k \wedge T_{y}^{W}>k\right)=p_{1}(k), \\
& { }_{k} p_{\overline{x y}}=\mathrm{P}\left(T_{x}^{M}>k \vee T_{y}^{W}>k\right)=p_{1}(k)+p_{2}(k)+p_{3}(k) .
\end{aligned}
$$

Hence, (3) can be rewritten as

$$
\ddot{b}_{\mathbf{S}^{b}}= \begin{cases}\frac{\beta W}{\sum_{k=0}^{n-1} v(k) \cdot{ }_{k} p_{x y}} & \text { for } \quad \mathbf{S}^{b}=\{1\} \text { and } n=\min \left\{\omega_{x}^{M}, \omega_{y}^{W}\right\} \quad(\mathrm{JLS}), \\ \frac{\beta W}{\sum_{k=0}^{n-1} v(k) \cdot{ }_{k} p_{\overline{x y}}} & \text { for } \quad \mathbf{S}^{b}=\{1,2,3\} \text { and } n=\max \left\{\omega_{x}^{M}, \omega_{y}^{W}\right\} \quad \text { (LSS). }\end{cases}
$$

Note that (7) is defined in the following way:

$$
{ }_{k} p_{\overline{x y}}=\mathrm{P}\left(T_{y_{0}}^{W}>t+k \mid T_{x_{0}}^{M}>s, T_{y_{0}}^{W}>t\right)+\mathrm{P}\left(T_{x_{0}}^{M}>t+k \mid T_{x_{0}}^{M}>s, T_{y_{0}}^{W}>t\right)-{ }_{k} p_{x y} .
$$

and (9) is different from that defined in Gerber (1995), Denuit et al. (2001):

$$
{ }_{k} p_{\overline{x y}}={ }_{k} p_{y}+{ }_{k} p_{x}-{ }_{k} p_{x y},
$$

where ${ }_{k} p_{x}=\mathrm{P}\left(T_{x}^{M}>k\right)=\mathrm{P}\left(T_{x}^{M}>s+k \mid T_{x_{0}}^{M}>s\right)$ and ${ }_{k} p_{y}=\mathrm{P}\left(T_{y}^{W}>k\right)$ (see also Youn et al,. 2002; Spreeuw, 2006).

For the calculation of annuity payments, we will apply formula (8), where the probabilities ${ }_{k} p_{x y}$ and ${ }_{k} p_{\overline{x y}}$ are specified by (6) and (9) respectively.

\section{Application}

\subsection{Copulas}

We investigate the Markov model based on the stationary Markov chain (see Wolthuis and Van Hoek, 1986; Norberg, 1989; Denuit et al., 2001). This model lets us establish the joint distribution of the lifetimes of spouses, i.e., $\left(T_{x}^{M}, T_{y}^{W}\right)$, for fixed $(x, y)$. 
Based on 2011 data for Lower Silesia (from Statistics Poland), Heilpern (2015) derived the empirical joint cumulative distribution function $F(w, z)$ for $x_{0}=y_{0}=60$ and Kendall's tau coefficient of correlation $\tau=0.073$ between the random variables $T_{x_{0}}^{M}$ and $T_{y_{0}}^{W}$. Heilpern (2015) also designated the copula $C(u, v)$, which described the dependence structure of the lifetimes $T_{x_{0}}^{M}$ and $T_{y_{0}}^{W}$. It was the following Gumbel copula:

$$
C(u, v)=\exp \left(-\left((-\ln u)^{\alpha}+(-\ln v)^{\alpha}\right)^{\frac{1}{\alpha}}\right),
$$

where $\alpha=1.0786$. The selection criterion was based on the distance between the empirical joint distribution function and a theoretical distribution function induced by the copula connected with Kendall's tau correlation coefficient, and it is estimated at the age $\left[x_{0}, 100\right)$ for men and at the age $\left[y_{0}, 100\right)$ for women.

Moreover, using data collected from Wroclaw (Lower Silesian capital) cemeteries in 2011, Heilpern (2015) appointed Kendall's tau coefficient of correlation $\tau=0.156$ between the random variables $T_{x_{0}}^{M}$ and $T_{y_{0}}^{W}$ for $x_{0}=y_{0}=0$. In the same way, the best copula from the considered function was chosen. It was the AMH copula:

$$
C(u, v)=\frac{u v}{1-\alpha(1-u)(1-v)},
$$

where $\alpha=0.5867$.

The copula determination methodology is described, for example, in Denuit et al. (2001), Genest et al. (1993) and Genest et al. (2009).

Using (10) or (11) we can calculate the value of $C^{*}\left(S^{M}(w), S^{W}(z)\right)$. The marginal survival function $S^{M}(w)$ and $S^{W}(z)$ can be calculated using the values of $l_{x_{0}}^{M}$ and $l_{y_{0}}^{W}$ from the Life Tables as follows:

$$
\begin{aligned}
& S^{M}(w)=\mathrm{P}\left(T_{x_{0}}^{M}>w\right)=\mathrm{P}\left(T_{0}^{M}>x_{0}+w \mid T_{0}^{M}>x_{0}\right)=\frac{l_{x_{0}+w}^{M}}{l_{x_{0}}^{M}}, \\
& S^{W}(z)=\mathrm{P}\left(T_{y_{0}}^{W}>z\right)=\mathrm{P}\left(T_{0}^{W}>y_{0}+z \mid T_{0}^{W}>y_{0}\right)=\frac{l_{y_{0}+z}^{W}}{l_{y_{0}}^{W}} .
\end{aligned}
$$

The values $l_{x_{0}+w}^{M}, l_{x_{0}}^{M}, l_{y_{0}+z}^{W}, l_{y_{0}}^{W}$ are taken from the Lower Silesia Life Table 2011 for men and women separately, which we obtained from Statistics Poland (not published). Substituting (12) and (13) for (4) and using (10), we obtain the survival Gumbel copula for Lower Silesia 2011, which may be used directly in Theorem 1 to calculate the probabilities $p_{i}(k)$. The same method can be used for the survival AMH copula for Wroclaw cemetery data. 


\subsection{Spot term rate}

The discounting factor $v(k)$ for $k=1,2, \ldots, n$ is given by (1) using the function $R(0, k)$. The parameters of the function $R(0, k)$ are estimated by using the least-squares method based on real Polish market data, related to the yield to maturity on zero-coupon and fixed-interest bonds from 3 March 2015 (source: http://bossa.pl/notowania/stopy/ rentownosc_obligacji). The estimation was made using the Solver in Microsoft Excel (Dębicka and Marciniuk, 2014; Charupat et al., 2016). We applied three models of spot interest rate, i.e., the Svensson model (sv), the Nelson-Siegel model (ns) and the Bliss model (bl). The data and all the functions of interest rate models are presented in Figure 3.

Figure 3: Spot interest rate model

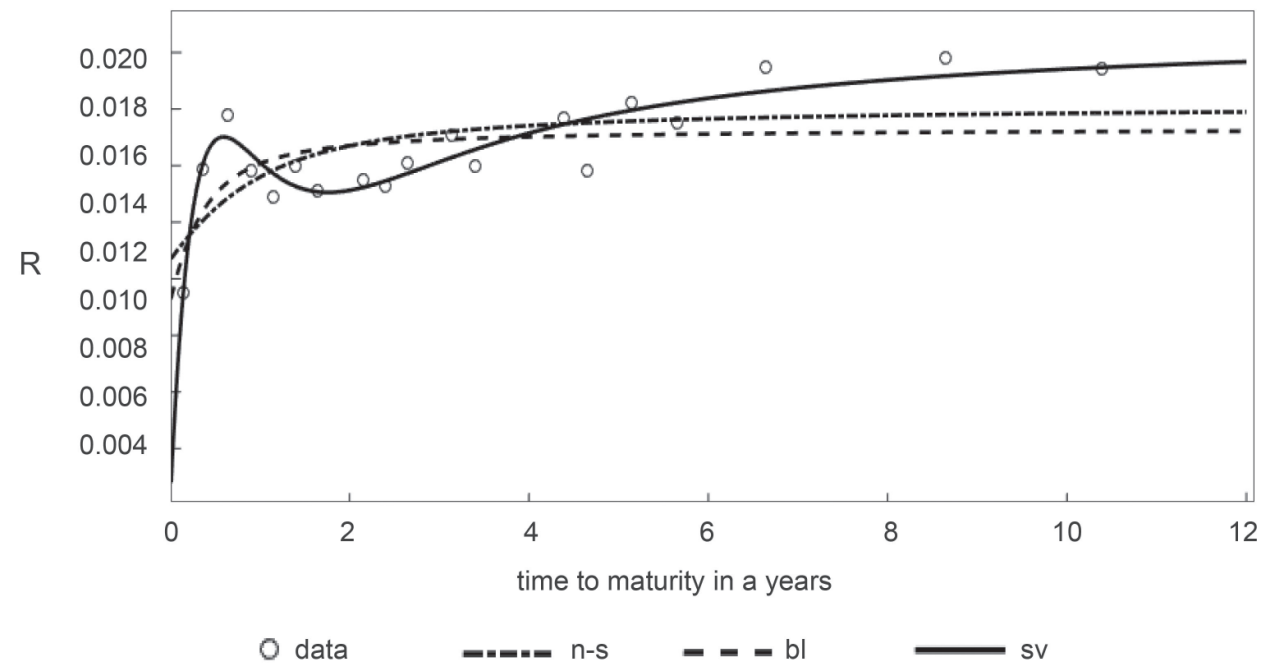

Source: Own elaboration

The best-fitting model is the Svensson model, which can be seen in Figure 3. Therefore, this model is used for the actuarial calculation. In this case, the function $R(0, k)$ has the following form (Anderson et al., 1996; Marciniuk, 2017):

where

$$
R(0, k)=\beta_{0}+\beta_{1} \frac{\tau_{1}}{k}\left(1-e^{-\frac{k}{\tau_{1}}}\right)+\beta_{2}\left(\frac{\tau_{1}}{k}\left(1-e^{-\frac{k}{\tau_{1}}}\right)-e^{-\frac{k}{\tau_{1}}}\right)+\beta_{3}\left(\frac{\tau_{2}}{k}\left(1-e^{-\frac{k}{\tau_{2}}}\right)-e^{-\frac{k}{\tau_{2}}}\right),
$$

$\beta_{0}=0.02096, \beta_{1}=-0.01684, \beta_{2}=0.05844, \beta_{3}=-0.05069, \tau_{1}=0.33388, \tau_{2}=0.57974$.

The parameter $\beta_{0}$ is the long-term rate. 


\subsection{Numerical example}

The numerical calculations presented in this part are made using own programs, written in MATLAB. We assume for the sake of simplicity that the value of property $W$ is equal to 100,000 PLN and $\beta=50 \%$. Our calculations are divided into two parts due to the two statuses of marriage reverse annuity contracts.

Table 2: Benefit of marriage reverse annuity contract in the case of JLS

\begin{tabular}{|c|c|c|c|c|c|c|c|}
\hline \multirow[t]{3}{*}{ JLS } & \multicolumn{7}{|c|}{ Woman's age } \\
\hline & \multirow{2}{*}{$\begin{array}{l}y \\
x\end{array}$} & \multicolumn{3}{|c|}{60} & \multicolumn{3}{|c|}{65} \\
\hline & & Gumbel & AMH & independ. & Gumbel & АMH & independ. \\
\hline \multirow{9}{*}{ Man's age } & 60 & $3,763.5$ & $3,653.6$ & $3,823.3$ & $4,050.3$ & $3,920.8$ & $4,131.7$ \\
\hline & 65 & $4,225.5$ & $4,115.0$ & $4,294.5$ & $4,468.5$ & $4,338.2$ & $4,570.3$ \\
\hline & 70 & $4,903.8$ & $4,795.3$ & $4,979.2$ & $5,103.9$ & $4,976.1$ & $5,221.6$ \\
\hline & 75 & $5,868.4$ & $5,767.1$ & $5,949.1$ & $6,030.2$ & $5,911.2$ & $6,159.8$ \\
\hline & 80 & $7,245.1$ & $7,156.7$ & $7,331.3$ & $7,374.4$ & $7,272.6$ & $7,514.0$ \\
\hline & 85 & $9,242.8$ & $9,172.4$ & $9,334.6$ & $9,344.5$ & $9,268.5$ & $9,493.9$ \\
\hline & \multicolumn{7}{|c|}{ Woman's age } \\
\hline & $y$ & & 70 & & & 75 & \\
\hline & $\mathbf{x}$ & Gumbel & AMH & independ. & Gumbel & AMH & independ. \\
\hline \multirow{9}{*}{ Man's age } & 60 & $4,524.6$ & $4,374.2$ & $4,625.7$ & $5,319.9$ & $5,148.6$ & $5,440.3$ \\
\hline & 65 & $4,888.5$ & $4,738.7$ & $5,026.6$ & $5,628.6$ & $5,458.6$ & $5,804.6$ \\
\hline & 70 & $5,458.8$ & $5,318.6$ & $5,634.9$ & $6,120.0$ & $5,972.1$ & $6,367.6$ \\
\hline & 75 & $6,319.1$ & $6,195.2$ & $6,525.6$ & $6,880.4$ & $6,773.8$ & $7,203.0$ \\
\hline & 80 & $7,601.3$ & $7,503.2$ & $7,830.9$ & $8,057.5$ & $8,002.8$ & $8,443.3$ \\
\hline & 85 & $9,515.1$ & $9,454.4$ & $9,763.2$ & $9,869.5$ & $9,876.3$ & $10,303.0$ \\
\hline & \multicolumn{7}{|c|}{ Woman's age } \\
\hline & $\mathbf{y}$ & \multicolumn{3}{|c|}{80} & \multicolumn{3}{|c|}{85} \\
\hline & $\mathbf{x}$ & Gumbel & AMH & independ. & Gumbel & AMH & independ. \\
\hline \multirow{6}{*}{ Man's age } & 60 & $6,610.1$ & $6,428.1$ & $6,752.0$ & $8,574.2$ & $8,409.9$ & $8,739.1$ \\
\hline & 65 & $6,866.0$ & $6,689.2$ & $7,083.3$ & $8,777.9$ & $8,632.7$ & $9,037.9$ \\
\hline & 70 & $7,275.5$ & $7,138.7$ & $7,603.9$ & $9,103.1$ & $9,028.0$ & $9,515.3$ \\
\hline & 75 & $7,908.8$ & $7,861.3$ & $8,383.4$ & $9,594.8$ & $9,677.6$ & $10,234.0$ \\
\hline & 80 & $8,915.1$ & $8,999.3$ & $9,552.4$ & $10,360.0$ & $10,723.0$ & $11,321.0$ \\
\hline & 85 & $10,546.0$ & $10,772.0$ & $11,325.0$ & $11,647.0$ & $12,389.0$ & $12,990.0$ \\
\hline
\end{tabular}

Source: Own elaboration 
First, we calculate the value of annuity in the case of Joint-Life Status according to Formula (8). To compare the impact of the two degrees of dependence of spouses' future lifetimes on the marriage benefit, we use the two copulas introduced above in the formulas for probabilities derived in Theorem 1. Moreover, we confront the results obtained for dependence and independence of spouses' future lifetimes. The benefits in the case of JLS are presented in Table 2 for $x, y \in\{60,65,70,75,80,85\}$. Note that for married couples in which the husband is older than the wife $(x>y)$, the annuity is higher than in the reverse situation $(x<y)$. The man's age has a greater impact on the amount of benefit (compare Figure 4 with Figure 5).

The value of benefit in the case of JLS for the woman's age depending on the man's age is presented in Figure 4 for $x \in\{60,61, \ldots, 90\}$ and $y \in\{60,70,80\}$. The value of benefit for the man's age depending on the woman's age is presented in Figure 5 for $y \in\{60,61, \ldots, 90\}$ and $x \in\{60,70,80\}$. We can observe that the benefit increases with spouses' growing age. Its value grows faster for older people.

Figure 4: Benefit for $y$ - year-old woman as a function of man's age $x$ in the case of JLS

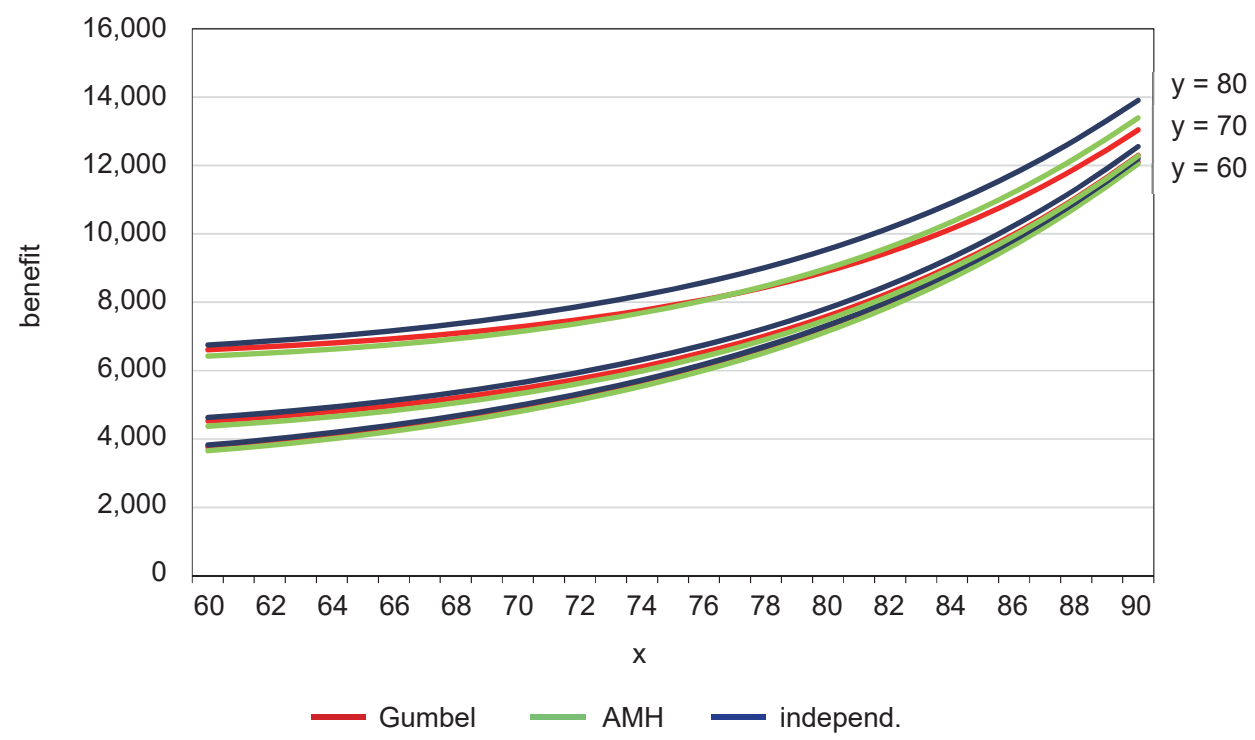

Source: Own elaboration 
Figure 5: Benefit for $x$-year-old man as a function of woman's age $y$ in the case of JLS

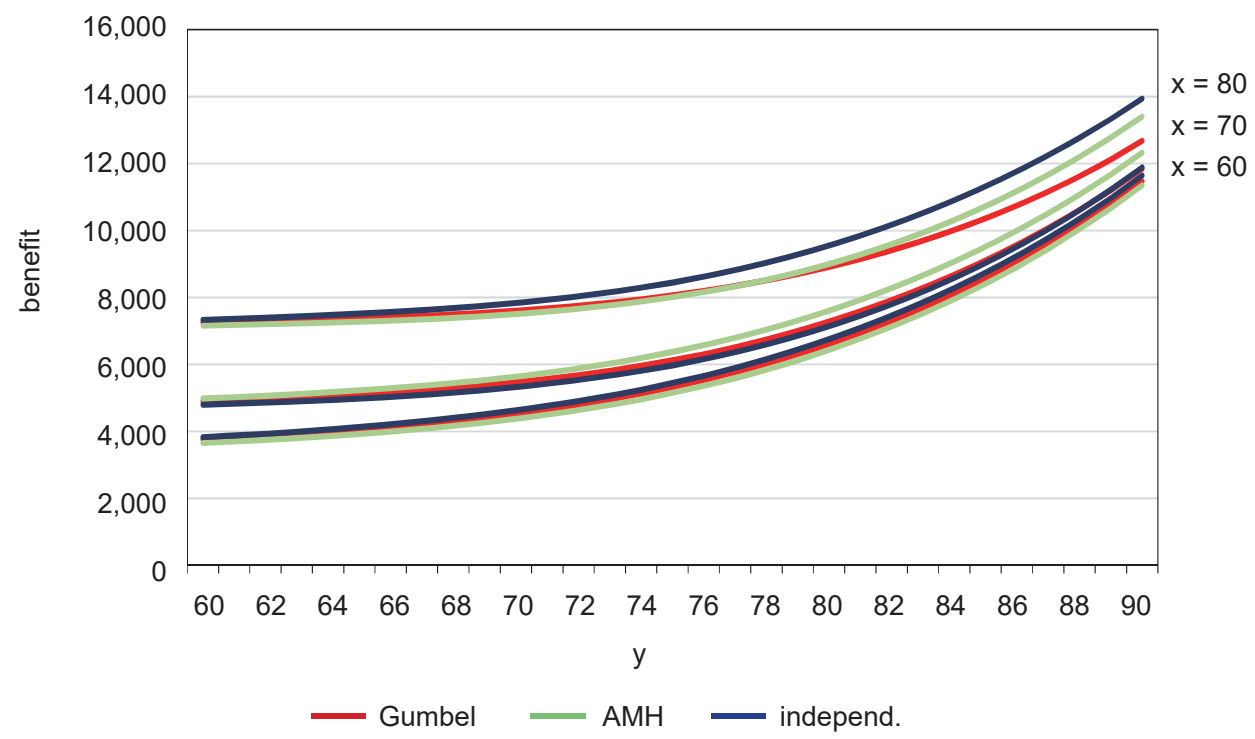

Source: Own elaboration

The highest benefit can be observed for spouses' independent future lifetimes for JLS. In this case, the benefit is overestimated. The benefit for the AMH function is the lowest for younger people. For spouses older than 75 years, this benefit is higher than for the Gumbel function and the relative increase defined as

$$
\text { relative increase }=\frac{\ddot{b}^{\text {independence }}-\ddot{b}^{\text {dependence }}}{\ddot{b}^{\text {dependence }}} \text {. }
$$

is not larger than $6 \%$ (for $x, y=85$ ). The relative increases of benefits for spouses' independent future lifetimes and for the Gumbel function first grow and then decrease with spouses' rising age in the case of JLS, which can be seen in Figure 6. For older people, this decrease is not noticeable. For younger men $(x \leq 75)$, the range of relative increase is from $2 \%$ to $4 \%$; for older men it can be even higher than $14 \%$.

The relative increase in benefits for spouses' independent future lifetimes and for the AMH function are more regular in the case of JLS. The relative difference first increases and then decreases with the woman's rising age. The range of relative difference varies from $1.75 \%$ to about $6 \%$ (see Figure 7 ). 
Figure 6: Relative increases between benefits for spouses' independent and dependent (Gumbel) future lifetimes in the case of JLS

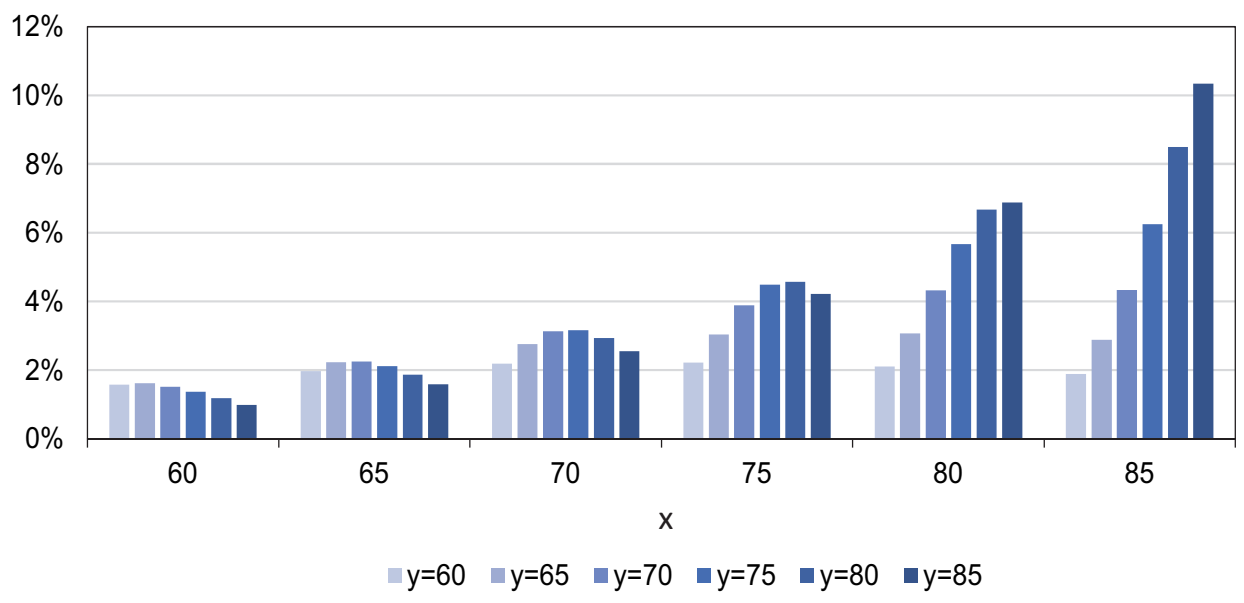

Source: Own elaboration

Figure 7: Relative increases between benefits for spouses' independent and dependent (AMH) future lifetimes in the case of JLS

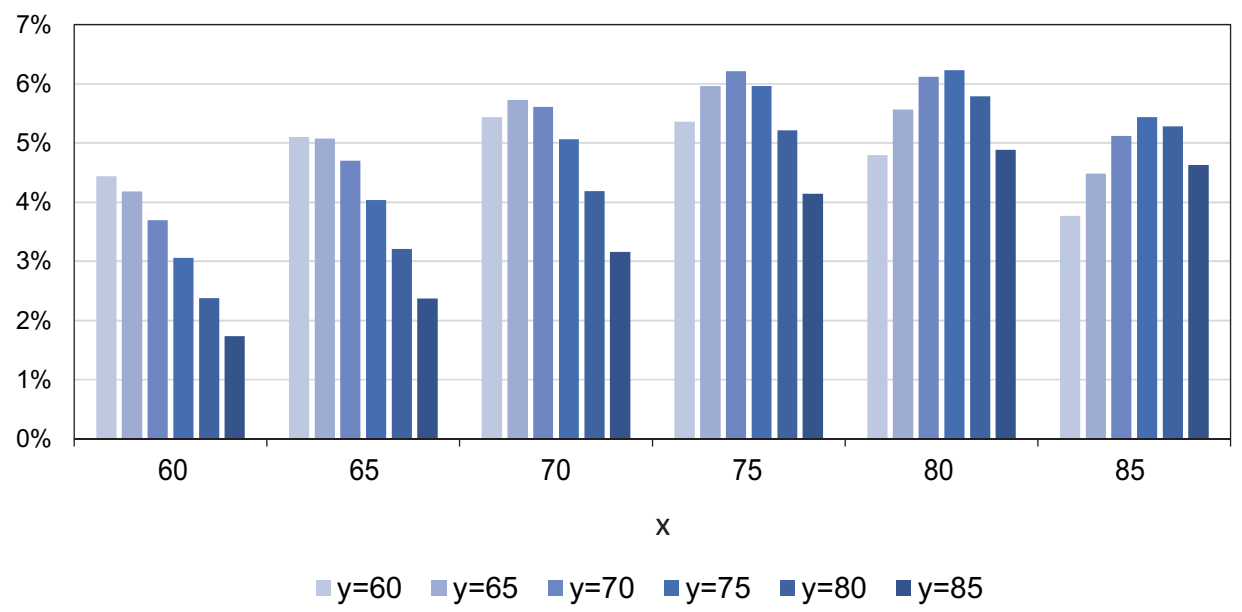

Source: Own elaboration

The second part of our results concerns the Last Surviving Status. The data on benefits in the case of LSS are presented in Table 3 for $x, y \in\{60,65,70,75,80,85\}$. The results were obtained according to Formula (8). 
Table 3: Benefit of marriage reverse annuity contract in the case of LSS

\begin{tabular}{|c|c|c|c|c|c|c|c|}
\hline \multirow[t]{3}{*}{ LSS } & \multicolumn{7}{|c|}{ Woman's age } \\
\hline & \multirow{2}{*}{$\begin{array}{l}\mathbf{y} \\
\mathrm{x}\end{array}$} & \multicolumn{3}{|c|}{60} & \multicolumn{3}{|c|}{65} \\
\hline & & Gumbel & AMH & independ. & Gumbel & AMH & independ. \\
\hline \multirow{9}{*}{ Man's age } & 60 & $2,412.7$ & $2,387.4$ & $2,388.7$ & $2,607.4$ & $2,583.9$ & $2,581.5$ \\
\hline & 65 & $2,487.5$ & $2,447.3$ & $2,476.4$ & $2,744.5$ & $2,705.8$ & $2,726.3$ \\
\hline & 70 & $2,537.3$ & $2,479.2$ & $2,545.1$ & $2,846.4$ & $2,787.6$ & $2,846.9$ \\
\hline & 75 & $2,561.0$ & $2,487.1$ & 2594.2 & $2,907.5$ & $2,829.4$ & $2,939.1$ \\
\hline & 80 & $2,561.4$ & $2,479.7$ & $2,627.4$ & $2,928.4$ & $2,840.4$ & $3,003.5$ \\
\hline & 85 & 2,539.6 & $2,466.0$ & $2,648.6$ & $2,911.4$ & $2,834.4$ & $3,045.3$ \\
\hline & \multicolumn{7}{|c|}{ Woman's age } \\
\hline & $\mathbf{y}$ & & 70 & & & 75 & \\
\hline & $\mathbf{x}$ & Gumbel & AMH & independ. & Gumbel & AMH & independ. \\
\hline \multirow{9}{*}{ Man's age } & 60 & 2,789.7 & $2,764.3$ & $2,770.5$ & 2,938.7 & $2,904.2$ & $2,938.8$ \\
\hline & 65 & $3,008.9$ & $2,971.2$ & $2,988.7$ & $3,252.1$ & $3,212.2$ & $3,244.6$ \\
\hline & 70 & $3,204.2$ & $3,146.6$ & $3,195.8$ & $3,572.9$ & $3,517.9$ & 3564.9 \\
\hline & 75 & $3,341.7$ & $3,263.4$ & $3,366.5$ & $3,857.9$ & $3,782.8$ & $3,872.6$ \\
\hline & 80 & $3,414.0$ & $3,325.8$ & $3,496.1$ & $4,048.0$ & $3,966.3$ & $4,128.9$ \\
\hline & 85 & $3,418.6$ & $3,348.0$ & $3,584.4$ & $4,123.5$ & $4,074.6$ & $4,324.2$ \\
\hline & \multicolumn{7}{|c|}{ Woman's age } \\
\hline & $\mathbf{y}$ & & 80 & & & 85 & \\
\hline & $\mathbf{x}$ & Gumbel & AMH & independ. & Gumbel & AMH & independ. \\
\hline \multirow{6}{*}{ Man's age } & 60 & $3,033.8$ & $2,983.3$ & $3,070.2$ & $3,062.2$ & $3,000.0$ & $3,158.5$ \\
\hline & 65 & $3,430.4$ & $3,382.1$ & $3,459.7$ & $3,511.5$ & $3,459.4$ & $3,612.9$ \\
\hline & 70 & $3,888.1$ & $3,837.2$ & $3,909.6$ & $4,072.9$ & $4,036.7$ & $4,177.0$ \\
\hline & 75 & $4,365.6$ & $4,303.5$ & $4,390.2$ & $4,739.4$ & $4,717.1$ & $4,841.1$ \\
\hline & 80 & $4,796.7$ & $4,731.6$ & $4,868.9$ & $5,462.7$ & $5,451.4$ & $5,576.8$ \\
\hline & 85 & $5,052.3$ & $5,046.4$ & $5,272.8$ & $6,126.4$ & $6,177.5$ & $6,344.7$ \\
\hline
\end{tabular}

Source: Own elaboration

For older people, under the assumption that future lifetimes of spouses are independent, the benefit is almost always higher than in other cases. This benefit is a little lower only for younger people than in the case of the Gumbel function (it is about $1 \%$ for the 60 -year-old men and it is about $0.5 \%$ for 65 -year-old men and 60 -year-old women); 
see Figure 8. The benefit for the AMH function is the lowest. However, for spouses older than 85 years, this benefit is higher than the benefit for the Gumbel function.

\section{Figure 8: Relative increases between benefits for spouses' independent and dependent (Gumbel) future lifetimes in the case of LSS}

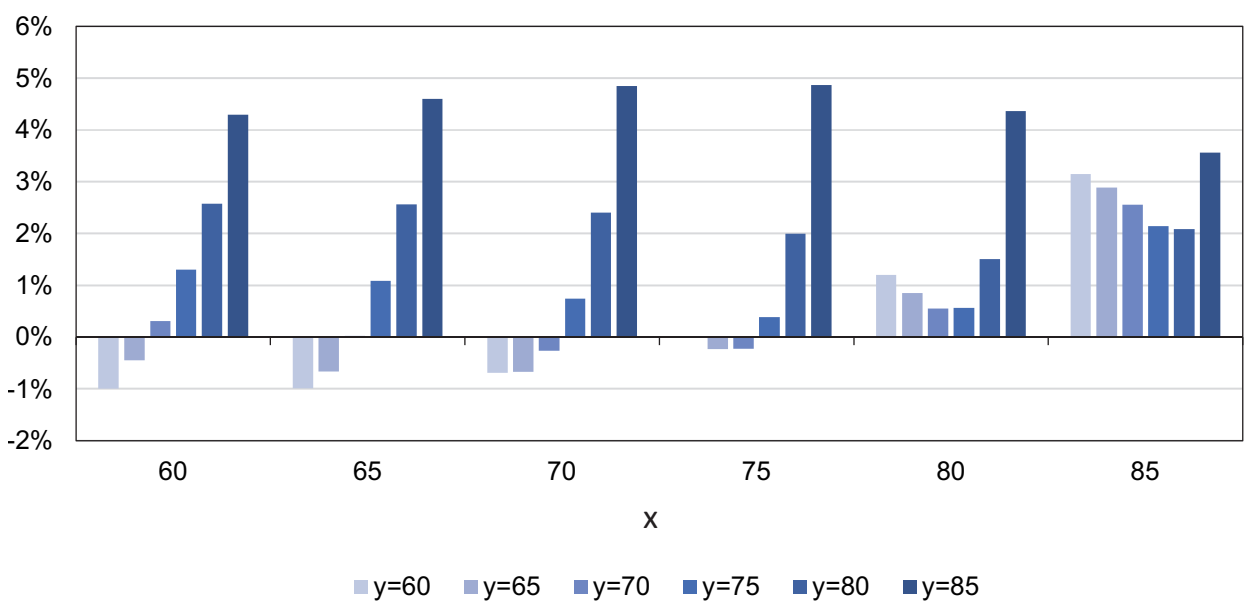

Source: Own elaboration

\section{Remark 1}

The benefit in the case of JLS presented in Table 2 is always greater in the independence cases than in the cases of Gumbel or AMH. For LSS we do not observe such regularities, differently from Denuit et al. (2001). For instance, for $x=y=60$, the benefit in the Gumbel case is greater than in the independence case, but for $x=80$ and $y=80$, we have the opposite situation. This fact results from differences in the definition of ${ }_{k} p_{\overline{x y}}($ see (7)).

In this case, the benefit also increases with spouses' rising ages. Similarly, its value grows faster for older people; however, the woman's age has a greater impact on the amount of benefit, which we can observe in Figures 9 and 10.

The benefit is much higher in the case of JLS than LSS, which can be seen in Figure 11. Moreover, the benefit is a convex function except in the case of LSS.

Finally, we would like to test the robustness of the benefit value to changing $\alpha$ coefficient values, i.e., the degree of dependency between spouses' future lifetimes. The example concerns the Last Surviving Status $\alpha \in\{0.5,0.56,0.5867,0.6,0.7\}$ when both spouses are of the same age $(x, y \in\{60,61, \ldots, 85\})$. The benefits for $W=100,000$ PLN are presented in Table 4. 
Figure 9: Benefit for $y$-year-old woman as a function of man's age $x$ in the case of LLS

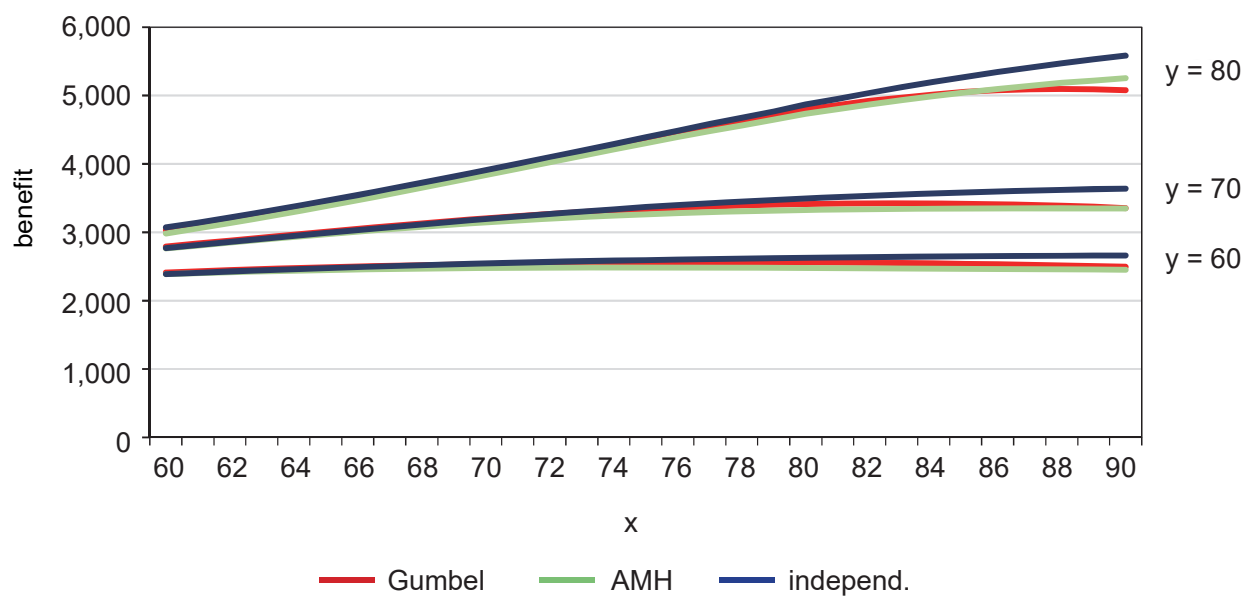

Source: Own elaboration

Figure 10: Benefit for $x$-year-old man as a function of woman's age $y$ in the case of LLS

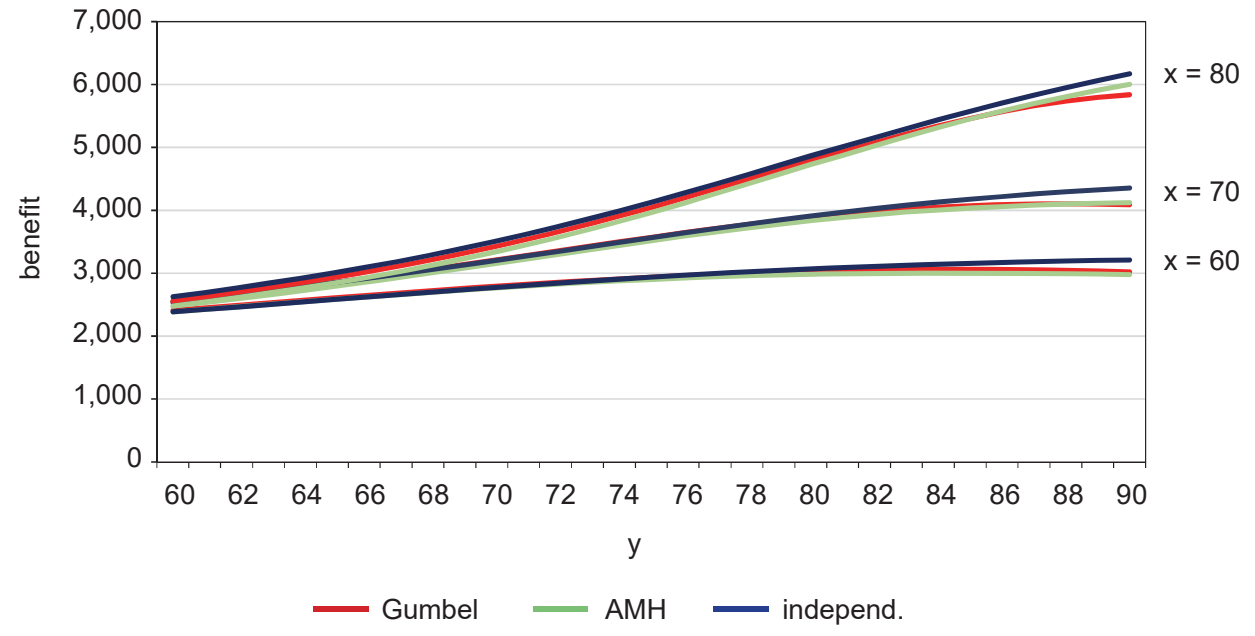

Source: Own elaboration 
Figure 11: Benefit for LSS and JLS for $y=80$

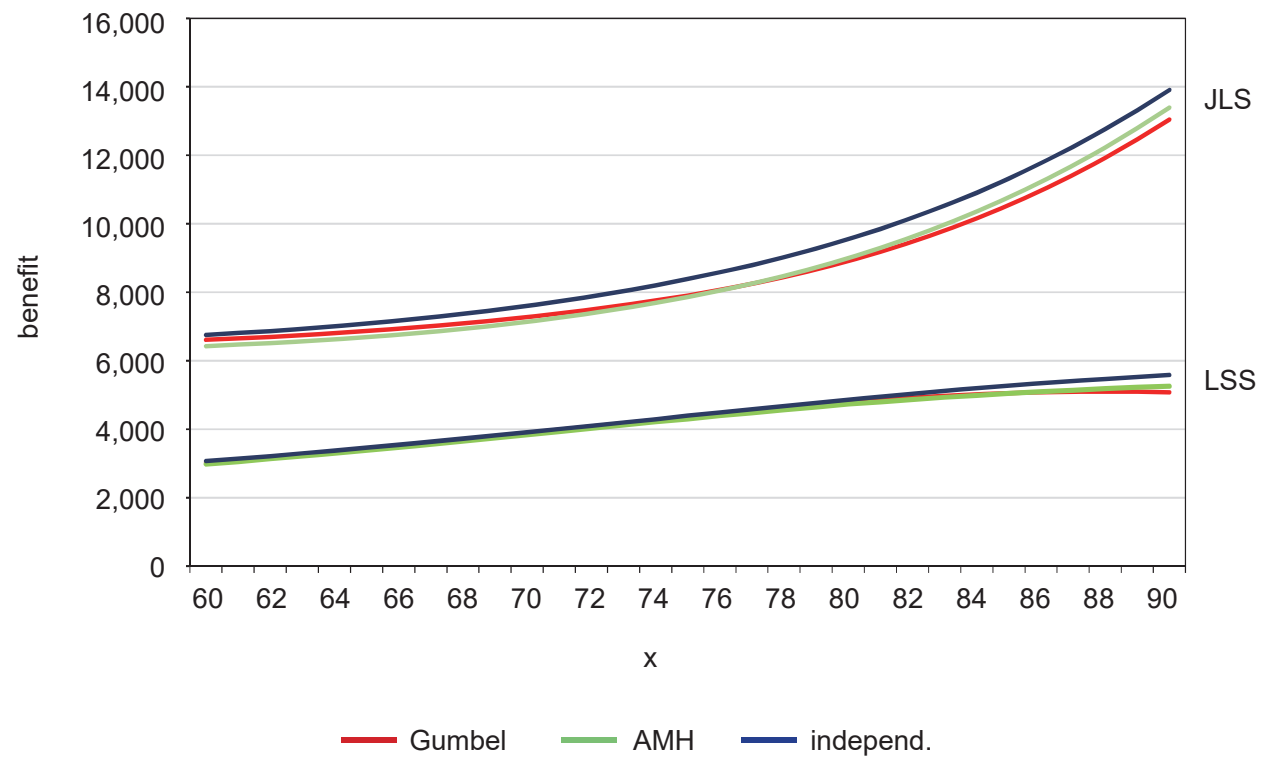

Source: Own elaboration

The benefits have similar values. The small differences between different values of Kendall's tau coefficient of correlation do not have a significant impact on the value of the benefit. 
Table 4: Copula resistance to $a$ coefficient in the case of LSS

\begin{tabular}{|c|c|c|c|c|c|}
\hline$a$ & 0.500 & 0.560 & 0.587 & 0.600 & 0.700 \\
\hline$\tau$ & 0.129 & 0.147 & 0.156 & 0.160 & 0.195 \\
\hline$x=y$ & \multicolumn{5}{|c|}{ Benefits } \\
\hline 60 & $2,388.0$ & $2,387.6$ & $2,387.4$ & $2,387.3$ & $2,386.6$ \\
\hline 61 & $2,444.7$ & $2,444.0$ & $2,443.7$ & $2,443.5$ & $2,442.4$ \\
\hline 62 & $2,504.9$ & $2,503.9$ & $2,503.4$ & $2,503.1$ & $2,501.5$ \\
\hline 63 & $2,568.8$ & $2,567.4$ & $2,566.7$ & $2,566.4$ & $2,564.2$ \\
\hline 64 & $2,636.7$ & $2,634.9$ & $2,634.0$ & $2,633.7$ & $2,630.9$ \\
\hline 65 & $2,709.0$ & $2,706.8$ & $2,705.8$ & $2,705.4$ & $2,702.1$ \\
\hline 66 & $2,786.2$ & $2,783.5$ & $2,782.3$ & $2,781.8$ & $2,778.0$ \\
\hline 67 & 2,868.6 & $2,865.5$ & 2,864.1 & 2,863.6 & 2,859.1 \\
\hline 68 & $2,956.9$ & $2,953.3$ & $2,951.7$ & $2,951.1$ & $2,946.0$ \\
\hline 69 & $3,051.5$ & $3,047.5$ & $3,045.7$ & $3,044.9$ & $3,039.2$ \\
\hline 70 & $3,153.2$ & $3,148.6$ & $3,146.6$ & $3,145.8$ & $3,139.4$ \\
\hline 71 & $3,262.5$ & $3,257.5$ & $3,255.2$ & $3,254.3$ & $3,247.2$ \\
\hline 72 & $3,380.3$ & $3,374.7$ & $3,372.2$ & $3,371.2$ & $3,363.4$ \\
\hline 73 & $3,507.5$ & $3,501.3$ & $3,498.6$ & $3,497.4$ & $3,488.9$ \\
\hline 74 & $3,644.8$ & $3,638.1$ & $3,635.1$ & $3,633.8$ & $3,624.5$ \\
\hline 75 & $3,793.4$ & $3,786.0$ & $3,782.8$ & $3,781.5$ & $3,771.3$ \\
\hline 76 & $3,954.3$ & $3,946.3$ & $3,942.8$ & $3,941.4$ & $3,930.4$ \\
\hline 77 & $4,128.7$ & $4,120.1$ & $4,116.3$ & $4,114.8$ & $4,103.0$ \\
\hline 78 & 4,317.9 & $4,308.7$ & $4,304.7$ & $4,303.0$ & $4,290.5$ \\
\hline 79 & $4,523.3$ & $4,513.5$ & $4,509.3$ & $4,507.5$ & $4,494.2$ \\
\hline 80 & $4,746.4$ & $4,736.1$ & $4,731.6$ & $4,729.8$ & $4,715.8$ \\
\hline 81 & $4,989.0$ & $4,978.2$ & $4,973.5$ & $4,971.6$ & $4,956.9$ \\
\hline 82 & $5,252.8$ & $5,241.6$ & $5,236.8$ & $5,234.8$ & $5,219.6$ \\
\hline 83 & $5,540.1$ & $5,528.6$ & $5,523.6$ & $5,521.5$ & $5,505.9$ \\
\hline 84 & $5,853.0$ & $5,841.3$ & $5,836.3$ & $5,834.1$ & $5,818.2$ \\
\hline 85 & $6,194.4$ & $6,182.6$ & $6,177.5$ & $6,175.4$ & $6,159.3$ \\
\hline
\end{tabular}

Source: Own elaboration 


\section{Conclusion}

The impact of the dependence between the future lifetimes of married partners on actuarial values was analysed in this article. The structure of the dependence of spouses' future lifetimes is modelled using a copula. For this purpose, we determine elements of the vector containing joint probabilities for an $x+k$-year-old man and a $y+k$-year-old woman (Theorem 1) which, in this case, is defined using Polish Life Tables and a copula for real Polish data. The cash flows of the marriage reverse annuity contract are calculated using Formula (8). Two cases of marriage reverse annuity contract are distinguished, i.e., joint-life status and last surviving status. Moreover, we take into account the real interest rate, determined based on data from the Polish market.

We compare the results for both statuses and the impact of the degree of the dependence and independence of spouses' future lifetimes in the last part. To sum up, the benefit is generally much higher for JLS than for LSS. The function of the benefit is convex for JLS, contrary to LSS. The benefit is higher for spouses' independent future lifetimes than for dependent ones in the case of JLS, which is more profitable for customers. In the case of LSS, the benefits for younger people are not higher than in the case of independence. However, for older people the result is similar to the case of JLS. The relative increase between benefits for the independent and dependent cases is significant. We show that the choice of the copula is important enough, but the small differences between different values of Kendall's tau coefficient of correlation do not have a significant impact on the value of the benefit. Even if the correlation coefficient is not calculated accurately, the results are not significantly different.

\section{References}

Anderson, N., Breedon, F., Deacon, M. et al. (1996). Estimating and Interpreting the Yield Curve. Chichester: John Wiley \& Sons. ISBN 0-471-96207-4.

Blake, D., Cairns, A., Coughlan, G. et al. (2013). The New Life Market. The Journal of Risk and Insurance, 80(3), 501-557, https://doi.org/10.1111/j.1539-6975.2012.01514.x

Blake, D., Morales, M. (2017). Longevity Risk and Capital Markets: The 2014-2015 Update. The Journal of Risk and Insurance, 84(S1), 279-297, https://doi.org/10.1111/jori.12213

Carriere, J. F. (2000). Bivariate Survival Models for Coupled Lives. Scandinavian Actuarial Journal, 1, 17-31, https://doi.org/10.1080/034612300750066700

Charupat, N., Kamstra, M. J., Milevsky, M. A. (2016). The Sluggish and Asymmetric Reaction of Life Annuity Prices to Changes in Interest Rate. The Journal of Risk and Insurance, 83(3), 519-555, https://doi.org/10.1111/jori.12061 
Denuit, M., Dhaene, J., Le Bailly de Tilleghem, C. et al. (2001). Measuring the Impact of a Dependence among Insured Lifelengths. Belgian Actuarial Bulletin, 1(1), 18-39, https://doi.org/10.1111/jori.12061

Dębicka, J. (2013). An Approach to the Study of Multistate Insurance Contracts. Applied Stochastic Models in Business and Industry, 29(3), 224-240, https://doi.org/10.1002/asmb.1912

Dębicka, J., Marciniuk, A. (2014). Comparison of Reverse Annuity Contract and Reverse Mortgage on the Polish Market. 17-th AMSE, Applications of Mathematics in Economics, International Scientific Conference: Poland, 27-31 August, 2014, Conference Proceedings, Wroclaw University Press, pp. 55-64. ISBN 978-83-7695-421-9, https://doi.org/10.15611/amse.2014.17.06

Frees, E. W. (1990). Stochastic Life Contingencies with Solvency Considerations. Transactions of the Society of Actuaries, 42, 91-148.

Genest, C., Rivest, L-P. (1993). Statistical Inference Procedures for Bivariate Archimedean Copulae. Journal of the American Statistical Association, 88(423), 1034-1043, https://doi.org/10.1080/01621459.1993.10476372

Genest, C., Remillard, B., Beaudoin, D. (2009). Goodness-of-fit Tests for Copulas: A Review and a Power Study. Insurance: Mathematics and Economics, 44(2), 199-213, https://doi.org/10.1016/j.insmatheco.2007.10.005

Gerber, H. U. (1990). Life Insurance Mathematics. Berlin, Heidelberg, New York: Springer-Verlag, https://doi.org/10.1007/978-3-662-02655-7

Gourieoux, C., Lu, Y. (2015). Love and Death: A Freund Model with Frailty. Insurance: Mathematics and Economics, 63, 191-203, https://doi.org/10.1016/j. insmatheco.2015.03.016

Haberman, S., Pitacco, E. (1999). Actuarial Models for Disability Insurance. Chapman \& Hall/CRC, https://doi.org/10.1201/9781315136622

Hanewald, K., Post, T., Sherris, M. (2016). Portfolio Choice in Retirement - What is the Optimal Home Equity Release Product? The Journal of Risk and Insurance, 83(2), 421-446, https://doi.org/10.2139/ssrn.2280883

Heilpern, S. (2015). Dependent Structure Induced by Markov Chain in the Multiple Life Insurance. 18-th AMSE, Applications of Mathematics in Economics, International Scientific Conference: Jindřichův Hradec, 2-6 September, 2015, Conference Proceedings, https://doi.org/10.15611/amse.2014.17.12. Available at: http://amse2015.cz/proceedings

Hoem, J. M. (1969). Markov Chain Models in Life Insurance. Blätter der Deutschen Gesellschaft für Versicherungsmathematik, 9(2), 91-107, https://doi.org/10.1007/bf02810082

Hoem, J. M. (1988). The Versatility of the Markov Chain as a Tool in the Mathematics of Life Insurance. Transactions of the 23rd International Congress of Actuaries, Helsinki, R, pp. 171-202.

Lee, Y-T., Wang, CH-W., Huang, H-CH. (2012). On the Valuation of Reverse Mortgages with Regular Tenure Payments. Insurance: Mathematic and Economics, 51(2), 430-441, https://doi.org/10.1016/j.insmatheco.2012.06.008 
Luciano, E., Spreeuw, J., Vigna, E. (2008). Modeling Stochastic Mortality for Dependent Lives. Insurance: Mathematics and Economics, 43(2), 234-244, https://doi.org/10.1016/j. insmatheco.2008.06.005

Luciano, E., Spreeuw, J., Vigna, E. (2016). Spouses' Dependence across Generations and Pricing Impact on Reversionary Annuities. Risks, 4(2), 1-18, https://doi.org/10.3390/ risks4020016

Marciniuk, A. (2017). Marriage Reverse Annuity Contract and Reverse Mortgage - Application of a Generalized Model of Reversionary Annuity, in Gardoń, A., Kozyra, C., Mazurek, E., eds., Applications of Mathematics and Statistics in Economics 2017. Conference Proceedings. Wrocław: Wrocław University of Economics Press, pp. 297-306. ISBN 978-83-7695-693-0, https://doi.org/10.15611/amse.2017.20.24

Nelsen, R. B. (1999). An Introduction to Copulas. New York: Springer. ISBN 0-387-98623-5, https://doi.org/10.1007/0-387-28678-0.

Norberg, R. (1989). Actuarial Analysis of Dependent Lives. Bulletin de l'Association Suisse des Actuaries, 40, 243-254.

Norberg, R. (2002). Basic Life Actuarial Mathematics - lifebook.pdf, www.math.ku.dk > $\sim$ mogens, lifebook.

Pitacco, E. (2014). Health Insurance. Basic Actuarial Models. EAA Series, Springer, ISBN 978-3-319-12235-9, https://doi.org/10.1007/978-3-319-1235-9

Potocký, R., Waldl, H., Stehlik, M. (2014). On Sums of Claim and Their Applications in Analysis of Pension Funds and Insurance Products. Prague Economics Papers, 23(3), 349-370, https://doi.org/10.18267/j.pep.488

Shao, A. W., Hanewald, K., Sherris, M. (2015). Reverse Mortgage Pricing and Risk Analysis Allowing for Idiosyncratic House Price. Insurance: Mathematic and Economics, 63, 76-90, https://doi.org/10.2139/ssrn.2393813

Spreeuw, J. (2006). Types of Dependence and Time-dependent Association between Two Times in Single Parameter Copula Models. Scandinavian Actuarial Journal, 5, 286-309, https://doi.org/10.1080/03461230600952880

Stallard, E. (2006). Demographic Issues in Longevity Risk Analysis. The Journal of Risk and Insurance, 73(4), 575-609, https://doi.org/10.1111/j.1539-6975.2006.00190.x

Youn, H., Shemyakin, A., Herman, E. (2002). A Re-examination of Joint Mortality Functions. North American Actuarial Journal, 6(1), 166-170, https://doi.org/10.1080/10920277.2002 .10596035

Wolthuis, H. (1994). Life Insurance Mathematics (The Markovian Model). CAIRE education Series, No. 2, Brussels.

Wolthuis, H., Van Hoek, L. (1986). Stochastic Models for Life Contingencies. Insurance: Mathematics and Economics, 5(3), 217-254, https://doi. org/10.1016/0167-6687(86)90034-x 